\title{
Influences of Welding Parameters on Friction Stir Welding of Aluminum and Magnesium: A Review
}

\author{
Boopathi Sampath ${ }^{1, a}{ }^{*}$, V. Haribalaji ${ }^{2, b}$ \\ ${ }^{1}$ Department of Mechanical Engineering, Muthayammal Engineering College, Rasipuram, Tamil \\ Nadu 637408, India \\ ${ }^{2}$ Department of Mechanical Engineering, Narasu Sarathy Institute of Technology, Salem. Tamil \\ Nadu 638401, India \\ *aboopasangee@gmail.com, bharimechnsit@gmail.com
}

Keywords: Aluminum, Magnesium, Friction Stir Welding, Joining Factor, Welding Quality, Defect-Free

\begin{abstract}
Friction stir welding (FSW) is an important joining process wherein two dissimilar metals and alloys are welded together using frictional heat produced in a revolving tool and workpiece. FSW is playing an important role in dissimilar material joining of Magnesium $(\mathrm{Mg})$ and Aluminum (Al) materials due to the increasing demand for their industrial applications. In this review article, the research background of FSW processes, and influences of joining factors on tensile strength, micro-hardness, and microstructures of FSW of Al-Mg alloy materials have been studied. The effects of joining factors for example axial force, tool revolving speed, tool incline, speed, and offset on welding characterizes have been enlightened to make defect-free FSW of aluminum and magnesium alloys. The microstructural behaviors of intermetallic formation and material drift in FSW zones of Al-Mg were also studied to find the scope to improve the welding quality.
\end{abstract}

\section{Introduction and background}

Friction stir welding (FSW) is an essential metal welding technique that was invented in 1991 by The Welding Institute (TWI). It had been first applied to join the two dissimilar alloys and metals by the application of frictional heat produced by a rotating tool and two metals $[1,2,6]$. The FSW process has been applied in the joining of non-ferrous materials such as Aluminum, Magnesium, and Copper alloys with high strength weight ratio. In a product assembly section of production industries, the welding of dissimilar alloys is challenging to improve the physical properties of joints in naval, aerospace, automotive, and various precision applications [24]. Tool revolving speed, tool feed rate, force applied and the tilting angle of FSW is general process parameters of the FSW of dissimilar Al-Mg components[24]. Banglong Fu et al. stated that the toughnessof welded joints was increased while locating $\mathrm{Mg}$ on the leading edge and offsetting tool of dissimilar metals (AA6061 and AZ31B) and it was reduced while placing Al on the leadingside and tool offsetting due to reducing heat absorption[11]. M. Azizieh et al. attempted to weld $3 \mathrm{~mm}$ thickness of plates (AA1100 and AZ31 Mg). Mg was either on the leading side or tailing side and the five modes of tool offset positions center line to $2.5 \mathrm{~mm}$ towards both $\mathrm{Al}$ and $\mathrm{Mg}$ sides. It was concluded that the quality welding was obtained from processes of advancing side and tool pin offset towards magnesium side; the hardness and tensile strength were also improved by the process in Al side [3]. Uday kumar et al. experimented that the $6 \mathrm{~mm}$ thickness Al 6061-T6 and AZ31 dissimilar alloy plates are welded using $600 \mathrm{rpm}$ tool rotation speed, $0.5 \mathrm{~mm} / \mathrm{s}$ to $1 \mathrm{~mm} / \mathrm{s}$ of tool travel speed, 10 tool tilting angle, and $16 \mathrm{~mm}$ diameter shoulder in the FSW. The

(c) (1) Content from this work may be used under the terms of the Creative Commons Attribution 3.0 license. Any further distribution of this work must maintain attribution to the author(s) and the title of the work, journal citation and DOI. Published under license by Materials Research Forum LLC. 
microstructures of welding characteristics have been analyzed to find the effects of the $\mathrm{Mg}$ and Alleading side and top of the weld. The welds nugget zones, intermetallic compound A112Mg17, and $\mathrm{A} 13 \mathrm{Mg} 2$, and $\mathrm{Al}-\mathrm{Mg}$ Alloy intermixing region were also investigated [16].

Very recently, Dharmalingam et al. testified from FSW experiments of Al-Mg that the maximum tool revolving speed and minimum tool feed rate were applied to improve the micro-grain structure and tensile strength while welding AA8011 and AZ31 Alloys [10]. H. H. Jadav et al. Co2 and compressed air were applied to cool the welding zone of dissimilar Al-Mg. the tensile capacity and hardness of the Al-Mg joints had been enhanced by the application of the Co 2 cooling method. In this process, $545 \mathrm{rpm}$ tool revolving speed, $31.5 \mathrm{~mm} / \mathrm{min}$ of tool feed rate, 2 degreesof tool tilt, and $2 \mathrm{~mm}$ tool offsetting to advancing side Magnesium alloy [12]. A $\mathrm{H}$ Baghdadi et al.[4] revealed from FSW that the uniform distribution of microstructure grain size in the joining zone and improved tensile capacity of FSW junction were observed from the post-weld heat-treatment process. A.Bandi et al. concluded that the intermetallic joining layer and the intermetallic mixture of AA6061-T6 and AZ31B-H24 magnesium plates were presented. It was also observed that A13Mg2 was obtained in the Aluminium side and a major Eutectic mixture of Al12Mg17 was derived in the Magnesium side [5].

It is observed from the above literature survey the major parameters for dissimilar FSW joining are tool revolving speed, tool travel feed, tool geometry, and axial forces are playing a major contribution in Al-Mg weld processes. Dissimilar material mixing and flow of intermetallic layers were influenced by the geometry of tool and pin length. In this paper, the impacts of joining parameters, microstructural characteristics, and mechanical behaviors of FSW joints Al-Mg alloys were elucidated.

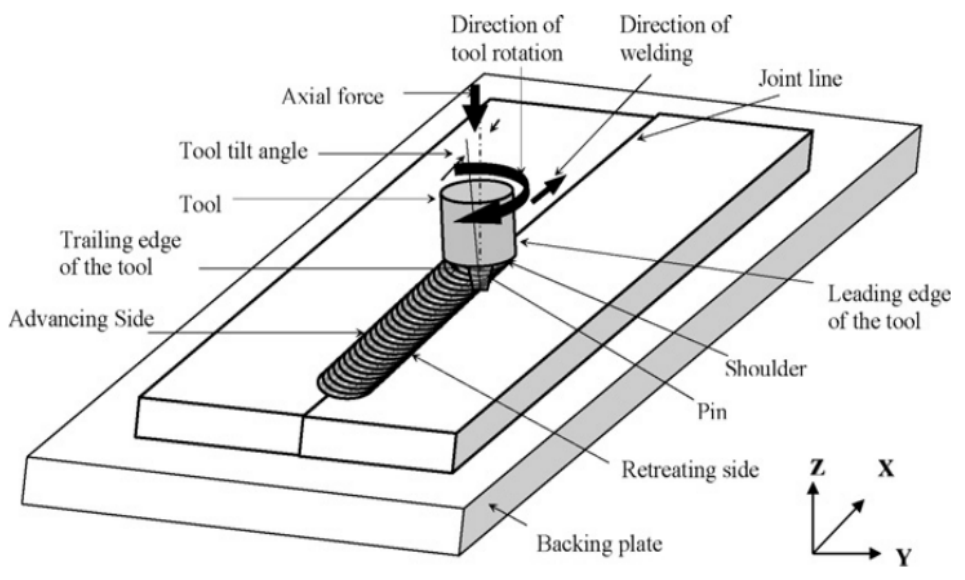

Figure 1. Schematic diagram of FSW [14]

\section{FSW experimentation}

The schematic experimental setup for FSW is shown in Figure 1. The work materials' size and shape were prepared based on the type of fixtures used in the FSW machine. Before the welding process, Aluminum and Magnesium plates were well cleaned by steel brush and acetone to remove the dust on the workpieces[9,21]. Locating these plates on the fixture is essential to joint dissimilar metals welding. The aluminum was connected to leading edge and the Magnesium was connected to tailing side to improve material flow and quality of welding joints.[13].The tool design is playing a significant role in uniform temperature distribution, the flow of welding metal, and the quality of intermetallic layers [21]. 

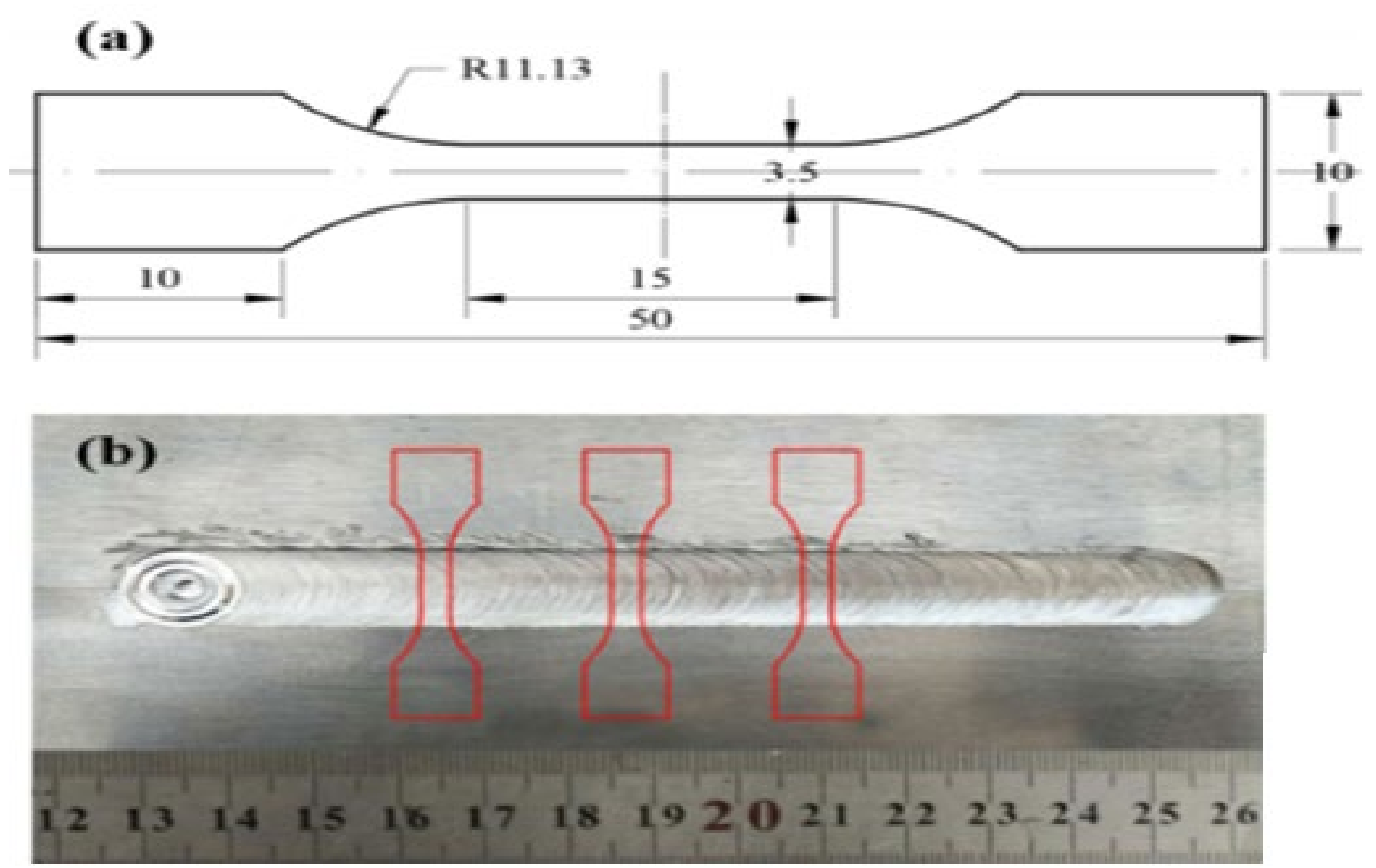

Figure 2. ASTM E8/E8M-09 Tensile testing specimens: (a) schematic (b) experiment[9]

After the FSW process, the hardness was observed on all three sides of welded specimens. Vickers hardness test for dissimilar Al-Mg joints was stirring zone as a center point and the hardness level was tested from center point to Al side or $\mathrm{Mg}$ Side. Before tensile testing, the weld samples were machined by EDM with ASTM E8/E8M-09 Standards as displayed in Figures 2 (a) and (b). The ultimate tensile, yield stress and amount of deformation of FSW weld specimens were measured by a universal testing machine. The welded parts were transversely cut from plates as per standard shape and size. The metallographic samples were polishing with different grade emery papers and the area of the part was chemically cleaned by a solution from acetic acid, ethanol, picric acid, and distilled water[8,13]. The macrostructure of weld joints was inspected by a laser microscope and the microstructure of weld zone like stir zone (SZ), Heat affected Zone (HAZ), and thermo mechanically affected zone (TMAZ) are performed by Transmission electron microscope (TEM) and scanning electron microscope (SEM). Aluminum and magnesium phase composition was detected by Energy dispersive spectrometer (EDS) and X-ray diffraction (XRD) methods[8,13].

\section{FSW - Al-MG alloy: characterization analysis}

Analysis of Microstructure

From this macrostructure analysis, the defects of the welding joint were examined by varying joiningfactorssuch as tool revolving speed, tool feed rate, and pin position. The cross-sectional morphologies of weld joints were examined the material flow and identify the defect formation in the weld zones[20]. Defects were found when the offset of the toolalong with the Aluminum plate and desired weld quality was recorded while tool offsetting onthe magnesium plate [19]. Material flow and IMCs were the two key features leads to defects in FSW welds. Friction between the tool and the aluminum alloy was generated more heat than $\mathrm{Mg}$ alloy. Tool offset towards aluminum side leads to more formation of IMCs and it produces hot cracking defects[26,27]. The 
intermetallic distribution is directly related to the peak temperature, the ratio between tool rotation and travel speed. The material flow rate is higher at high rotational speed by excessive liquation and is lower at a very low speed of rotation[3]. The good quality of weld joints between Al-Mg dissimilar alloys is attained by placing magnesium alloy on the advancing side [7].
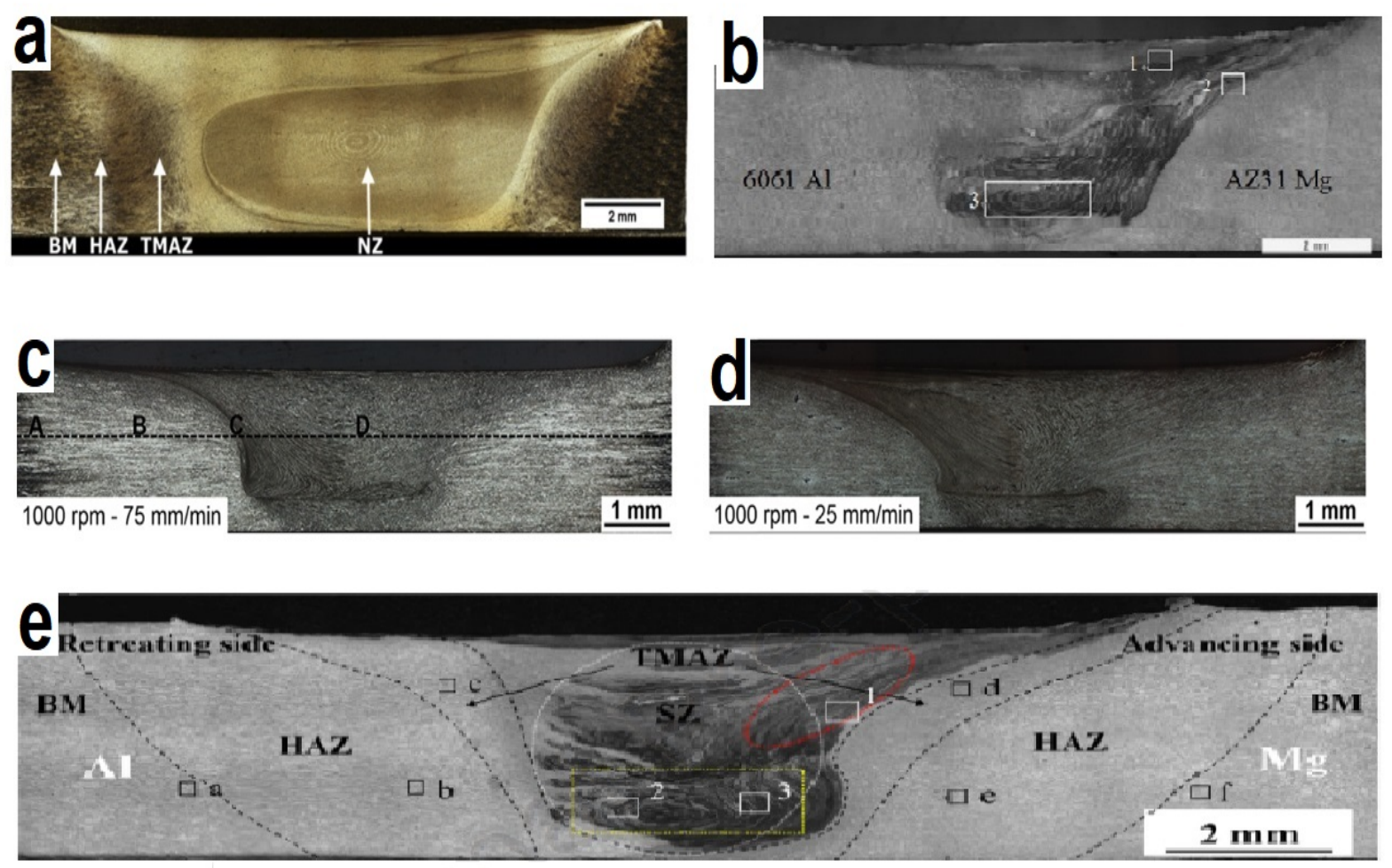

Figure 3. Macrostructure of FSW zone of Al-Mg[8,9,17,23]

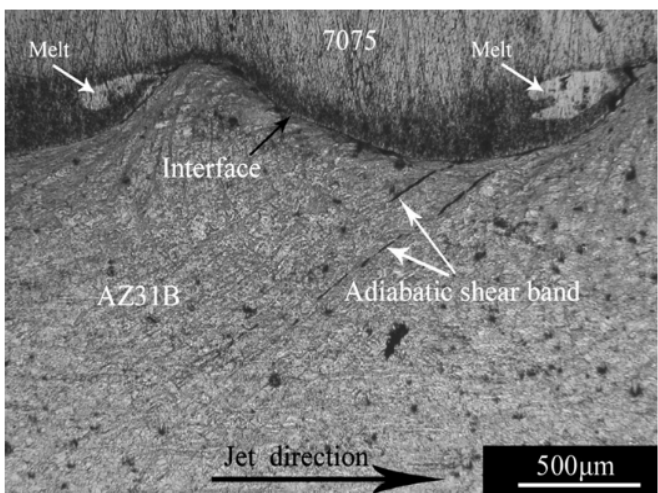

(a)

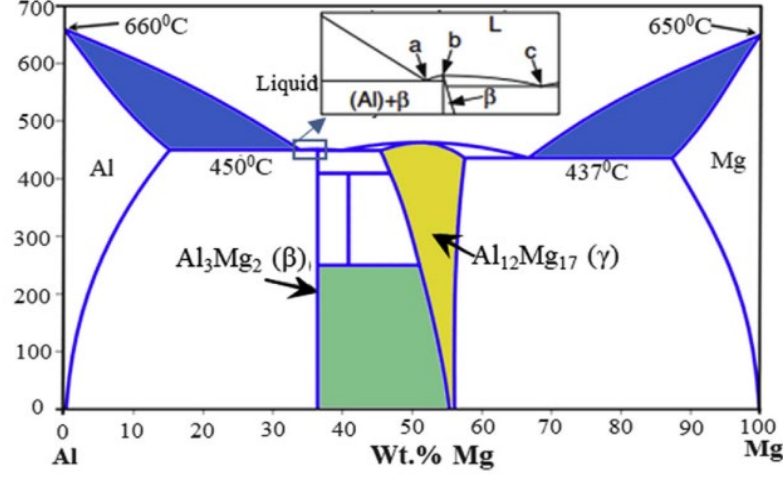

(b)

Figure 4.(a) Microstructure in AZ31B/7075 (b) shear band and phase diagram of Al-Mg alloys [15]

In the FSW region of the Al-Mg welded joint, the material flow and IMCs were examined by SEM and EDS images. The intermetallic layer and bonding of Al-Mg joints were shown in Figures 3(a),(b), (c), (d) and (e). The four different weld zones like SZ, TMAZ, HAZ, and BM were analyzed with the help of microstructural images. While FSW operation, a particular volume of 
metal was debris in the intermediate zone of Al-Mg and intermixed material was finally settled down in SZ. In the IMCs phases, A112Mg17 and Al3Mg2 were formed across the Al-Mg zone pictures are displayed in Figure 4 (a) and the concentration distribution of Al-Mg atoms was formed as displayed in figure 4(b) [15].

A typical SEM image and EDX images are shown in Fig.4 (a \& b). Nugget zones are further classified into three different zones to examine the Al-Mg intercalated structure and the formation of the intermetallic eutectic structure of $\mathrm{Al}_{12} \mathrm{Mg}_{17}$ and $\mathrm{Al}_{3} \mathrm{Mg}_{2}$. Moreover, IMCs $\mathrm{Al}-\mathrm{Mg}$ solid solutions were indicated by XRD patterns[11]. Instead of the conventional FSW process, the ultrasonic-assisted FSW was found to enhance the IMC stream thickness as a maximum of $58 \%$ was reported with peak vibration condition. The acoustic assistance had considerably improved the material deform and intermixing of dissimilar Al-Mg. From the ultrasonic-assisted FSW process, the interconnected zone of the joints was significantly modified [15].

After microstructure analysis of the PWHT method, the grain size of SZ increased several hundred microns and this phenomenon was the instability of the microstructure of the joining phase [4].
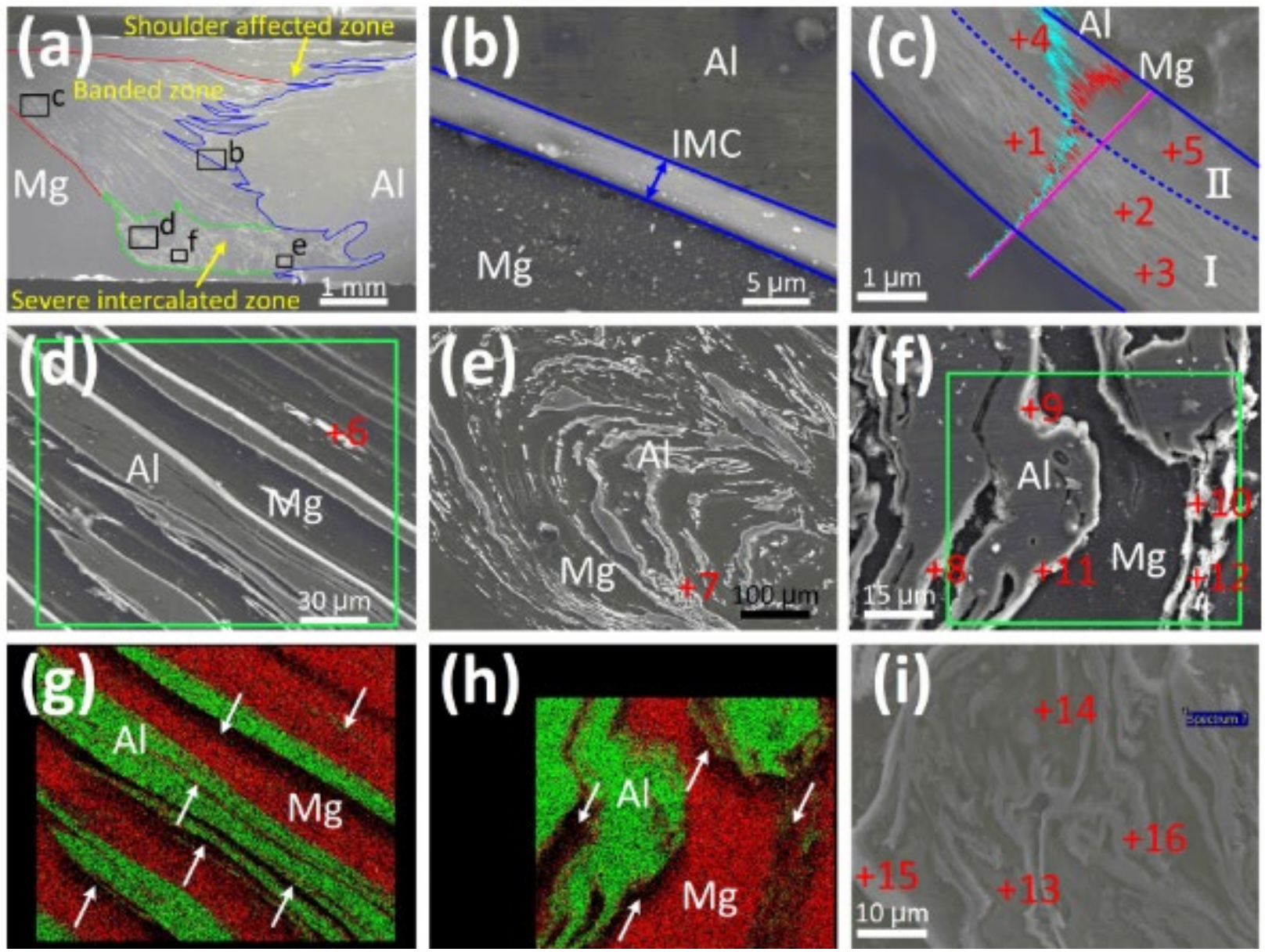

Figure 5. SEM and EDX image ofFSW - Al-Mg (a) cross-section, (b, $d-f$, i) Enlarges views(a), (c) EDX line of interface, (g) EDX mapping of zone (d), (h) EDX mapping phase [11]

From this microstructure analysis of the FSW process, the material intermixing, heat affected the weld zones and the intermixing of Al-Mg alloy were analyzed to enhance the weld properties. 
It has been gathered that the IMCs stream and grain structure of the FSW process was improved than the conventional welding process.

\section{Analysis of Microhardness}

The hardness was obtained on three area zone of the weld specimens. Vickers hardness test for dissimilar Al-Mg joints was stirring zone as a center point and the hardness level was tested from center point to Al side or Mg Side. In dissimilar Al-Mg alloys welding process, the hardness was $86 \mathrm{Hv}$ for $\mathrm{Mg}$ alloy set near the leading edge and $89 \mathrm{Hv}$ for $\mathrm{Mg}$ alloy set on the trailing edge, this small modification on hardness value was due to material flow and IMC stream of Al and $\mathrm{Mg}$ [20]. The internal heat was reduced when increasing the tool offset to the Mg plate and the morphology of IMCs was distributed more homogeneous and the hardness value was declined[18]. The strong ultrasonic vibration can break the IMCs into fragments and enhance the finer grain size compared to conventional FSW and the mean hardness value of NZ was significantly increased[19]. At the area of the Nugget zone, a sharp connection line was identified and the hardness value reduced rapidly at the Al side. Hardness variation was decreased at NZ and the total hardness was enhanced due to grain resettlement of the revolving tool point[22]. The hardness in that zone is decreased when referred to as HAZ and TMAZ. Thus, the hardness of the PWHAZ was significantly enhanced while comparing with the existing FSW process [4]. The hardness value of the weld zone was improved by low weld speed and decreased while the increase in feed rate.

From this study of hardness analysis for dissimilar Al-Mg welding, the hardness was decreased at weld zones when compared to base metals of Al-Mg alloys. Instead of the conventional FSW process, the average hardness value was increased in ultrasonic-assisted FSW and post-weld heat treatment processes due to the fine grain structure of IMCs layers of the weld zone. The SEM and EDX images of FSW : Al-Mg are displayed in Figures 5(a), (b), (c), (d), (e), (f), (g) and (h).

\section{Analysis of Tensile strength}

In the FSW Al-Mg, the tensile capacity of the FSW joint in Mg placed on the advanced side of FSW was obtained as $172.3 \mathrm{MPa}$ and the $\mathrm{Al}$ on the advanced side was found $156.25 \mathrm{MPa}$ because of the formation of IMCs in dissimilar welds[20]. The tensile property of welded joints was reduced by $38 \%$ while comparing with base metals due to coarse grain size in Heat-affected zone and the tensile strength was increased by $15 \%$ by the post-weld heat treatment process[4]. The average tensile strength has been improved to contain the level of welding speed. Further increasing speed, the strength is reduced. The highest strength value of $477 \mathrm{MPa}$ was obtained from the mean welding velocity and the highest tool revolving velocity. The worst tensile properties were found in the highest welding speed due to the loose bonding structure[17]. The maximum tensile strength for dissimilar Al-Mg alloys was observed from maximum tool revolution speed and lower feed rate. It is also obtained from the cylindrical tool than the straight square profile of the tool pin[10]. It was also found that the great tensile property $(143 \mathrm{MPa})$ was attained from the highest tool revolving speed $(1400 \mathrm{rpm})$ and lowest tool travel $\mathrm{rate}(100 \mathrm{~mm} / \mathrm{min})$, and the joint efficiency is nearly equivalent to $72 \%[25]$. The maximum elongation was found from $500 \mathrm{rpm}$ of tool revolving velocity and moving feed of $20 \mathrm{~mm} / \mathrm{min}[3]$.

It was revealed from the literature that the weld parameter of high revolving speed and low tool feed were found to highest tensile strength and the highest percentage of deformation of Al-Mg alloy joining processes. 


\section{Summary}

- In this article, FSW of Aluminium and Magnesium alloy was considered to understand the influences of various joining factors on tensile strength, microhardness, and microstructure of welding zone by various Al-Mg alloys researchers.

- The defects-free friction-stir-welding have been found from macrostructure analysis and optimal quality weld joints have been attained by changing the factors such as tool revolving speed, travel feed, tilt angle, and tool offset.

- IMCs layer and material flow of FSW from various research activities have been summarized with the evidence of the SEM and EDX images. IMCs growth was found by providing an additional cooling system during the FSW process. The welding zone grain structure and enhance weld strength have been enhanced by the PWHT method.

- The tensile property and microhardness of FSW Al-Mg joints were improved in ultrasonic-assisted FSW than conventional FSW process.

\section{References}

[1] R. Allen, T. Thomson, Friction welding, Chinese Patent., (1986).

[2] R. V Arunprasad, G. Surendhiran, M. Ragul, T. Soundarrajan, S. Moutheepan, S. Boopathi, Review on Friction Stir Welding Process, Int. J. Appl. Eng. Res. ISSN., 13 (2018) 5750-5758.

[3] M. Azizieh, A. Sadeghi Alavijeh, M. Abbasi, Z. Balak, H.S. Kim, Mechanical properties and microstructural evaluation of AA1100 to AZ31 dissimilar friction stir welds, Materials Chemistry and Physics., 170 (2016) 251-260. https://doi.org/10.1016/j.matchemphys.2015.12.046

[4] A.H. Baghdadi, Z. Sajuri, M.Z. Omar, A. Rajabi, Friction stir welding parameters: Impact of abnormal grain growth during post-weld heat treatment on mechanical properties of $\mathrm{Al}-\mathrm{Mg}-\mathrm{Si}$ welded joints, Metals., 10 (2020) 1-18. https://doi.org/10.3390/met10121607

[5] A. Bandi, S.R. Bakshi, Effect of Pin Length and Rotation Speed on the Microstructure and Mechanical Properties of Friction Stir Welded Lap Joints of AZ31B-H24 Mg Alloy and AA6061-T6 Al Alloy, Metallurgical and Materials Transactions A: Physical Metallurgy and Materials Science., 51 (2020) 6269-6282. https://doi.org/10.1007/s11661-020-06020-8

[6] S. Boopathi, A. Kumaresan, N. Manohar, R. Krishna Moorthi, Review on Effect of Process Parameters-Friction Stir Welding Process, International Research Journal of Engineering and Technology (IRJET), 4 (2017).

[7] G. Buffa, D. Baffari, A. Di Caro, L. Fratini, Friction stir welding of dissimilar aluminiummagnesium joints: Sheet mutual position effects, Science and Technology of Welding and Joining., 20 (2015) 271-279. https://doi.org/10.1179/1362171815Y.0000000016

[8] W. Chen, W. Wang, Z. Liu, D. An, N. Shi, T. Zhang, M. Ding, Microstructure evolution mechanism of $\mathrm{Al} / \mathrm{Mg}$ dissimilar joint during friction stir welding, Metallurgical Research \& Technology., 117 (2020) 311. https://doi.org/10.1051/metal/2020012

[9] W. Chen, W. Wang, Z. Liu, X. Zhai, G. Bian, T. Zhang, P. Dong, Improvement in tensile strength of $\mathrm{Mg} / \mathrm{Al}$ alloy dissimilar friction stir welding joints by reducing intermetallic 
compounds, Journal of Alloys and Compounds., (2020) 157942.

https://doi.org/10.1016/j.jallcom.2020.157942

[10] S. Dharmalingam, K. Lenin, P. Navaneetha Krishnan, Comparative analysis of cylindrical thread and straight square profile pin on ultimate tensile strength of AA8011/AZ31B in friction stir butt welding, Materials Today: Proceedings., 21 (2020) 523-526. https://doi.org/10.1016/j.matpr.2019.06.661

[11] B. Fu, G. Qin, F. Li, X. Meng, J. Zhang, C. Wu, Friction stir welding process of dissimilar metals of 6061-T6 aluminum alloy to AZ31B magnesium alloy, Journal of Materials Processing Technology., 218 (2015) 38-47. https://doi.org/10.1016/j.jmatprotec.2014.11.039

[12] H.H. Jadav, V. Badheka, D.K. Sharma, G. Upadhyay, Effect of pin diameter and different cooling media on friction stir welding of dissimilar Al-Mg alloys, Materials Today: Proceedings., (2020). https://doi.org/10.1016/j.matpr.2020.09.553

[13] S.A. Khodir, T. Shibayanagi, Dissimilar friction stir welded joints between 2024-T3 aluminum alloy and AZ31 magnesium alloy, Materials Transactions., 48 (2007) 2501-2505. https://doi.org/10.2320/matertrans.MRA2007093

[14] K. Kumar, S. V. Kailas, The role of friction stir welding tool on material flow and weld formation, Materials Science and Engineering A., 485 (2008) 367-374.

https://doi.org/10.1016/j.msea.2007.08.013

[15] S. Kumar, C. Wu, Suppression of intermetallic reaction layer by ultrasonic assistance during friction stir welding of $\mathrm{Al}$ and $\mathrm{Mg}$ based alloys, Journal of Alloys and Compounds., 827 (2020) 154343. https://doi.org/10.1016/j.jallcom.2020.154343

[16] U. Kumar, U. Acharya, S.C. Saha, B.S. Roy, Microstructure and mechanical property of friction stir welded Al-Mg joints by adopting modified joint configuration technique, Materials Today: Proceedings., 26 (2019) 2083-2088. https://doi.org/10.1016/j.matpr.2020.02.450

[17] Y. Li, H. Yan, J. Chen, W. Xia, B. Su, T. Ding, X. Li, Influences of welding speed on microstructure and mechanical properties of friction stir welded Al-Mg alloy with high $\mathrm{Mg}$ content, Materials Research Express., 7 (2020). https://doi.org/10.1088/2053-1591/ab9854

[18] H. Liu, Y. Chen, Z. Yao, F. Luo, Effect of tool offset on the microstructure and properties of AA6061/AZ31B friction stir welding joints, Metals., 10 (2020) 1-9.

https://doi.org/10.3390/met10040546

[19] Z. Liu, X. Meng, S. Ji, Z. Li, L. Wang, Improving tensile properties of Al/Mg joint by smashing intermetallic compounds via ultrasonic-assisted stationary shoulder friction stir welding, Journal of Manufacturing Processes., 31 (2018) 552-559. https://doi.org/10.1016/j.jmapro.2017.12.022

[20] S. MD, A.K. Birru, Mechanical and metallurgical properties of friction stir welded dissimilar joints of AZ91 magnesium alloy and AA 6082-T6 aluminium alloy, Journal of Magnesium and Alloys., 7 (2019) 264-271. https://doi.org/10.1016/j.jma.2018.09.004

[21] J. Mohammadi, Y. Behnamian, A. Mostafaei, H. Izadi, T. Saeid, A.H. Kokabi, A.P. Gerlich, Friction stir welding joint of dissimilar materials between AZ31B magnesium and 6061 aluminum alloys: Microstructure studies and mechanical characterizations, Materials Characterization., 101 (2015) 189-207. https://doi.org/10.1016/j.matchar.2015.01.008 
[22] B.L. Prasad, G. Neelaiah, M.G. Krishna, S.V.V. Ramana, K.S. Prakash, G. Sarika, G.P.K. Reddy, R. Dumpala, B.R. Sunil, Joining of AZ91 Mg alloy and Al6063 alloy sheets by friction stir welding, Journal of Magnesium and Alloys., 6 (2018) 71-76. https://doi.org/10.1016/j.jma.2017.12.004

[23] O.S. Salih, N. Neate, H. Ou, W. Sun, Influence of process parameters on the microstructural evolution and mechanical characterisations of friction stir welded Al-Mg-Si alloy, Journal of Materials Processing Technology., 275 (2020) 116366.

https://doi.org/10.1016/j.jmatprotec.2019.116366

[24] Y.S. Sato, S.H.C. Park, M. Michiuchi, H. Kokawa, Constitutional liquation during dissimilar friction stir welding of Al and Mg alloys, Scripta Materialia., 50 (2004) 1233-1236. https://doi.org/10.1016/j.scriptamat.2004.02.002

[25] I. Shigematsu, Y.J. Kwon, N. Saito, Dissimilar friction stir welding for tailor-welded blanks of aluminum and magnesium alloys, Materials Transactions., 50 (2009) 197-203. https://doi.org/10.2320/matertrans.MER2008326

[26] Y.B. Yan, Z.W. Zhang, W. Shen, J.H. Wang, L.K. Zhang, B.A. Chin, Microstructure and properties of magnesium AZ31B-aluminum 7075 explosively welded composite plate, Materials Science and Engineering A., 527 (2010) 2241-2245. https://doi.org/10.1016/j.msea.2009.12.007

[27] Y.K. Yang, H. DongG, S. Kou, Liquation Tendency and Liquid-Film, Welding Journal., 87 (2008) 202-211. 